\title{
Validity of ultrasonography-derived predictions for estimating skeletal muscle volume: a systematic literature review
}

\author{
Rasmus Liegnell ${ }^{1 *}$ (D), Fredrik Wessman ${ }^{1}$, Adel Shalabi $^{2}$ and Marita Harringe ${ }^{1}$
}

\begin{abstract}
Background: The amount of muscle volume (MV) varies between individuals and is important for health, wellbeing and performance. Therefore, the monitoring of MV using different imaging modalities is important. Magnetic resonance imaging (MRI) is considered the gold standard, but is not always easily accessible, and the examinations are expensive. Ultrasonography (US) is a much less expensive imaging method widely used to measure changes in muscle thickness (MT). Whether MT may translate into MV needs further investigation.
\end{abstract}

Purpose: The aim of this review is to clarify whether US-derived equations based on MT predict MV based on MRI.

Methods: A systematic literature review was conducted according to the PRISMA statement, searching the electronic databases PubMed, CINAHL and Web of Science, for currently published equations to estimate MV with US.

Results: The literature search resulted in 363 citations. Twelve articles met the eligibility criteria. Ten articles scored eight out of eleven on QUADAS and two scored nine. Thirty-six prediction equations were identified. $R$ values ranged between 0.53 and 0.961 and the standard error of the estimate (SEE) ranged between 6 and 12\% for healthy adult populations, and up to $25.6 \%$ for children with cerebral palsy. Eight studies evaluated the results with a Bland-Altman plot and found no systematic errors. The overall strength and quality of the evidence was rated "low quality" as defined by the GRADE system.

Conclusions: The validity of US-derived equations based on MT is specific to the populations from which it is developed. The agreement with MV based on MRI is moderate with the SEE ranging between 6 and 12\% in healthy adult populations. Suggestions for future research include investigations as to whether testing positions or increasing the number of measuring sites could improve the validity for prediction equations.

Keywords: Bland-Altman analysis, Magnetic resonance imaging, Muscle thickness, Muscle volume, Prediction equation, Ultrasonography

\section{Background}

Skeletal muscle accounts for about $40 \%$ of total body weight. Its primary function is to generate force and create physical movement essential for everyday living,

\footnotetext{
*Correspondence: rasmus.liegnell@gmail.com

1 Stockholm Sports Trauma Research Centre, Department of Molecular

Medicine and Surgery, Karolinska Institute, Stockholm, Sweden

Full list of author information is available at the end of the article
}

health and performance [1]. Skeletal muscle is also an endocrine organ, secreting a collection of factors called myokines that seem to have positive health effects on a variety of organs throughout the body [2]. The amount of muscle mass or muscle volume (MV) varies between individuals and is influenced by a complex interaction between nutrition, physical load, hormones, age, injuries and diseases [1]. MV gradually declines with age, which eventually may lead to sarcopenia, affecting $10 \%$ 
to $50 \%$ of individuals above 65 years of age [3]. Sarcopenia is associated with an increased risk of being hospitalized and all-cause mortality $[4,5]$. On the other hand, an increased or high amount of total MV seems to be protective and reduce the likelihood of common diseases and disabilities like cardiovascular disease, diabetes and immobility [6-8].

MV is strongly correlated with the ability to produce force and is therefore a good predictor for strength, through the ability to create joint torque (force $\mathrm{x}$ moment arm) $[9,10]$. Decreased MV and reduced strength are common after an injury, surgery, or immobilization. Meier et al. [11] reported that after knee arthroplasty an inability to activate quadriceps contributed to the loss in strength the first few months and that quadriceps $\mathrm{MV}$ was a strong predictor of strength after more than one year. Quadriceps MV is also predictive of patientreported function and persistent strength deficit after anterior cruciate ligament (ACL) reconstruction [12].

Hypertrophy is often seen as a way to improve strength in performance, rehabilitation or the activities of daily living. One of the main outcomes after repeated sessions of loading, through exercise or heavy daily activities, is the growth of contractile proteins within the skeletal muscle, leading to hypertrophy and an increase in MV [13]. The skeletal muscle is a plastic tissue that constantly adapts to the exposure and requirements in life. Therefore, valid measurements of MV and the changes in mass over time are of great interest in order to ensure that the intervention causes hypertrophy and muscle growth. Direct measurement of the changes in protein synthesis is possible but requires muscle biopsies and expensive tracers [14, 15]. Measurement of MV is achievable with high validity via the water displacement method [16] but this requires that the muscle be removed from its owner making it impossible to measure living beings and changes between different occasions.

Imaging is a useful tool to reduce suffering and enable non-invasive measurement of MV. Magnetic resonance imaging (MRI) or computed tomography (CT) are considered the gold standard [17]. MRI is preferable since $\mathrm{CT}$ involves radiation. The method for estimating MV measured with MRI $\left(\mathrm{MV}_{\mathrm{MRI}}\right)$ is determined by measuring a muscle's single axial anatomical cross-sectional area (ACSA), in multiple sections along the entire length of the muscle, and then multiplying ACSA by the length of each section [18]. MRI is not always easily accessible, and the examinations are expensive. Therefore ultrasonography (US) has become a widely used method to measure changes in muscle thickness (MT). Several studies have measured the acute and long-term differences in MT with US, before and after a period of exercise [19-21]. MT dimensions are measured as the distance from the subcutaneous adipose tissue muscle interface to the muscle bone interface [22]. MT is well correlated to the MRI cross-sectional area (CSA) in both the lower [23] and upper extremities [24].

Estimating MV with US ( $\left.\mathrm{MV}_{\mathrm{US}}\right)$ is commonly based on MT measurement and is achieved by developing prediction equations through multiple regression analysis including limb length or other anthropometric variables $[9,25]$. The true value of MV is unknown but since MRI is considered the gold standard, it would be best if the results from $M V_{U S}$ and the results from $M V_{M R I}$ were the same. When comparing $M V_{U S}$ to the water displacement method, standard error of the estimate (SEE) between 10 and 13\% have been reported [16]. Similar SEE percentages are reported when $M V_{M R I}$ and $M V_{U S}$ are compared [25]. Even though SEE varies, the correlation in a population should be good, since both methods aim to measure the same thing [26]. If the more accessible US can estimate MV in a satisfying manner it would be valuable to the clinician.

Therefore, the aim of this study was to perform a systematic literature review with the purpose of collecting the currently published equations to calculate $M V_{U S}$ and clarify how well US-derived equations based on muscle thickness predict $M V_{M R I}$.

\section{Methods}

\section{Search strategy}

The study was conducted according to the PRISMA statement [27]. A systematic search took place on the 30th of January, 2020, in the electronic databases PubMed, CINAHL and Web of Science. MeSH terms were identified and used whenever possible. MeSH terms "ultrasonography" and "magnetic resonance imaging" were used as a concept and combined with Boolean operator AND. Search terms "muscle thickness" and "muscle volume" were used as a concept and combined with Boolean operator OR. Both concepts were combined with Boolean operator AND. Investigators (RL and FW) screened the titles of all articles identified and, if eligible, the abstracts were read and discussed. Unless both investigators agreed that the study did not meet the eligibility criteria, the study was included for full text review. There was consensus between both investigators regarding eligibility during the full text review. Reference lists of the studies included were screened for eligible literature.

\section{Eligibility criteria}

To be included, the studies needed to meet the following criteria: 1: Measure MT with B-mode US. 2: Use US-derived equations based on MT to predict MV. 3: Use MRI as the reference method for MV. 4: Be published in the English language. Criteria for exclusion 
were the following: 1: Published before the year 2000 . 2: Animal studies. 3: Cadaver studies. 4: Reviews.

\section{Quality assessment}

To assess the quality of the included studies, a translated version of the Quality Assessment of Diagnostic Accuracy Studies (QUADAS) [28] published by the Swedish Agency for Health Technology, Assessment and Assessment of Social Services was used. Investigators (RL and FW) assessed each study independently, and thereafter discussed each study until consensus was reached. Group Reading Assessment and Diagnostic Evaluation (GRADE) was used to assess the overall strength and quality of the evidence [29].

\section{Ethical considerations}

All the studies included declared that written or informed consent had been given by study participants. In three studies, the participants were children or adolescents below the age of 18: these studies had obtained consent from their parents [30-32]. Most included studies declared that they had received approval from an independent ethics committee, with the exception of two studies [33,34] where there were no such declarations.

\section{Statistical analysis}

Two Bland-Altman plots were created from the mean values identified in the included studies, with the purpose of examining the agreement between the two methods in a descriptive manner. The values reported in $\mathrm{cm}^{3}$ and $\mathrm{kg}$ were separated into different plots. Both plots were plotted against the mean value of $M V_{M R I}$ and $M V_{U S}$ for every segment. The BIAS, standard deviation (SD), and upper and lower limits of agreement were calculated and reported as a percentage, according to the method described by Bland and Altman [26].

\section{Results}

The literature search resulted in 299 citations in the PubMed database, 23 in CINAHL and 41 in Web of Science. After abstracts had been analysed and discussed, 21 articles were selected for full text review. In the end, 12 articles met the eligibility criteria and were included in the systematic literature review (Fig. 1). Ten articles scored eight out of eleven on the QUADAS score and two scored nine out of eleven (Table 1). All articles lacked the same items on the QUADAS score, and stated that it was unclear whether those who analysed the index test were blinded to the results of the reference test, and vice-versa.

In total, the studies included 591 subjects. Five studies included only men $[9,33-36]$. Four studies included both men and women [25, 37-39]. Two studies

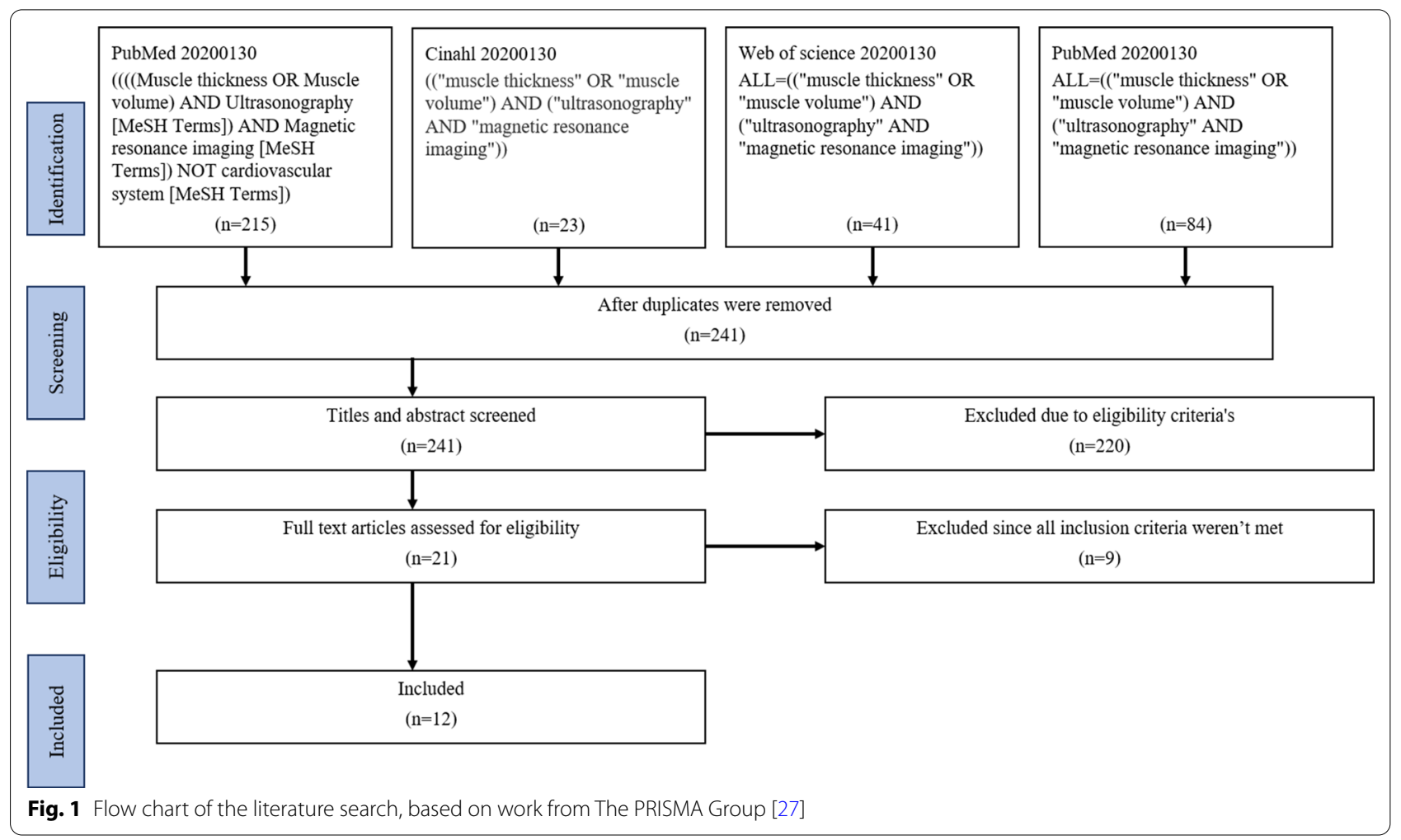


Table 1 Descriptive data

\begin{tabular}{|c|c|c|c|c|c|c|c|}
\hline Subjects & Body part & $\begin{array}{l}\text { Mean } \mathrm{MV}_{\text {MRI }}[ \pm \text { SEM }] \\
( \pm \text { SD })\end{array}$ & $\begin{array}{l}\text { Mean MV } \\
( \pm \text { SD })\end{array}$ & Position MRI & Position UL & QUADAS & References \\
\hline \multirow[t]{2}{*}{26 ơ (23-34y) } & Anterior upper arm & $297.5[14.9] \mathrm{cm}^{3}$ & $273.6[15.4] \mathrm{cm}^{3}$ & Supine & Standing & $8 / 11$ & {$[35]$} \\
\hline & Posterior upper arm & $405.4[22.6] \mathrm{cm}^{3}$ & $387.9[30.9] \mathrm{cm}^{3}$ & & & & \\
\hline \multirow[t]{2}{*}{26 ơ (x 25.7y) } & Anterior upper arm & & & Supine & Standing & $8 / 11$ & [9] \\
\hline & Posterior upper arm & & & & & & \\
\hline 46 ơ (20-70y) & Anterior upper thigh & $1637.5(383.51) \mathrm{cm}^{3}$ & $1660.7(386.2) \mathrm{cm}^{3}$ & Supine & Standing & $8 / 11$ & [33] \\
\hline \multirow[t]{4}{*}{27 ơ (X 25.3y) } & Anterior upper arm & $311.5(68.5) \mathrm{cm}^{3}$ & & Supine & Standing & $8 / 11$ & {$[34]$} \\
\hline & Posterior upper arm & $427.0(112.2) \mathrm{cm}^{3}$ & & & & & \\
\hline & Anterior upper thigh & $1825.3(428) \mathrm{cm}^{3}$ & & & & & \\
\hline & Posterior lower leg & $1072.7(226.3) \mathrm{cm}^{3}$ & & & & & \\
\hline \multirow[t]{5}{*}{72 đoㅇ (18-61y) } & Total body & $20.2(6.5) \mathrm{kg}$ & $19.6(6.5) \mathrm{kg}$ & Supine & Standing & $8 / 11$ & {$[37]$} \\
\hline & Arm & $2.0(0.7) \mathrm{kg}$ & $1.9(0.7) \mathrm{kg}$ & & & & \\
\hline & Trunk & $8.3(2.9) \mathrm{kg}$ & $8.2(2.8) \mathrm{kg}$ & & & & \\
\hline & Thigh & $7.7(2.6) \mathrm{kg}$ & $7.5(2.2) \mathrm{kg}$ & & & & \\
\hline & Lower leg & $2.2(0.6) \mathrm{kg}$ & $2.2(0.6) \mathrm{kg}$ & & & & \\
\hline $\begin{array}{l}10 \text { Prepubertal } \\
\text { children }\end{array}$ & Total body & $9.9(1.4) \mathrm{kg}$ & $9.5(1.1) \mathrm{kg}$ & Supine & Standing & $8 / 11$ & {$[30]$} \\
\hline$(\not>9.2 y)$ ot & Arm & $0.8(0.1) \mathrm{kg}$ & $0.7(0.1) \mathrm{kg}$ & & & & \\
\hline \multirow[t]{3}{*}{ (X 10.3y) 우 } & Trunk & $4.3(0.7) \mathrm{kg}$ & $4.7(0.6) \mathrm{kg}$ & & & & \\
\hline & Thigh & $3.6(0.6) \mathrm{kg}$ & $3.3(0.6) \mathrm{kg}$ & & & & \\
\hline & Lower leg & $1.1(0.2) \mathrm{kg}$ & $0.7(0.1) \mathrm{kg}$ & & & & \\
\hline 21 Adolescents & Total body & $17.4(3.8) \mathrm{kg}$ & $17.5(4.3) \mathrm{kg}$ & & & & \\
\hline (X 14.1y) ô & Arm & $1.5(0.4) \mathrm{kg}$ & $1.5(0.4) \mathrm{kg}$ & & & & \\
\hline \multirow[t]{3}{*}{$(X 13.8 y)$ 웅 } & Trunk & $7.3(1.6) \mathrm{kg}$ & $7.5(1.7) \mathrm{kg}$ & & & & \\
\hline & Thigh & $6.6(1.5) \mathrm{kg}$ & $6.5(1.8) \mathrm{kg}$ & & & & \\
\hline & Lower leg & $2.0(0.4) \mathrm{kg}$ & $1.9(0.5) \mathrm{kg}$ & & & & \\
\hline 147 ơ? (19-77y) & Anterior upper arm & $182.2(65.4) \mathrm{cm}^{3}$ & $179.4(62) \mathrm{cm}^{3}$ & Supine & Standing & $8 / 11$ & {$[25]$} \\
\hline 20 ઠீ? (20-41y) & Inner upper thigh & $19.70(9.29) \mathrm{cm}^{3}$ & & Supine & Standing & $9 / 11$ & [38] \\
\hline 9 children* (2-6y) & $\begin{array}{l}\text { Posterior lower leg } \\
\text { medial \& lateral }\end{array}$ & $11.92(9.12) \mathrm{cm}^{3}$ & & Did not report & Prone & $8 / 11$ & {$[32]$} \\
\hline \multirow[t]{5}{*}{60 ð (6-12y) } & Total body & $9113(2241) \mathrm{cm}^{3}$ & $8942(2841) \mathrm{cm}^{3}$ & Supine & Standing & $8 / 11$ & {$[31]$} \\
\hline & Arm & $851(198) \mathrm{cm}^{3}$ & $825(194) \mathrm{cm}^{3}$ & & & & \\
\hline & Trunk & $3495(795) \mathrm{cm}^{3}$ & $3453(780) \mathrm{cm}^{3}$ & & & & \\
\hline & Thigh & $3579(1026) \mathrm{cm}^{3}$ & $3484(986) \mathrm{cm}^{3}$ & & & & \\
\hline & Lower leg & $1164(295) \mathrm{cm}^{3}$ & $1180(323) \mathrm{cm}^{3}$ & & & & \\
\hline \multirow[t]{5}{*}{37 우 (6-12y) } & Total body & $7688(2339) \mathrm{cm}^{3}$ & $7804(2461) \mathrm{cm}^{3}$ & & & & \\
\hline & Arm & $743(208) \mathrm{cm}^{3}$ & $719(232) \mathrm{cm}^{3}$ & & & & \\
\hline & Trunk & $2798(519) \mathrm{cm}^{3}$ & $2982(929) \mathrm{cm}^{3}$ & & & & \\
\hline & Thigh & $2905(905) \mathrm{cm}^{3}$ & $3030(1015) \mathrm{cm}^{3}$ & & & & \\
\hline & Lower leg & $1084(344) \mathrm{cm}^{3}$ & $1074(346) \mathrm{cm}^{3}$ & & & & \\
\hline 60 우우 (51-77y) & Anterior upper thigh & $1000(373.3) \mathrm{cm}^{3}$ & $1019.5(370.9) \mathrm{cm}^{3}$ & Supine & Standing & $8 / 11$ & [39] \\
\hline 61 ơ (X 20.4y) & Total body & $38.5(5.8) \mathrm{kg}$ & $38.5(5.7) \mathrm{kg}$ & Prone & Standing & $9 / 11$ & {$[36]$} \\
\hline
\end{tabular}

SEM, standard error of the mean. SD, standard deviation. $X$, mean in sample. $y$, years. ${ }^{\circ}$, boys and males. $q$, girls and females

${ }^{*}$ Nine children with bilateral involvement spastic CP (6 $\sigma^{*}$ and 3 \% ) in total, 18 lower limbs were evaluated

included prepubertal children [30,31]. One study also included adolescents [30] and one study included children with cerebral palsy [32]. Descriptive data are presented in Table 1.
A total of 12 different body parts or muscle groups were measured, and 36 different prediction equations were identified. Correlations between $\mathrm{MV}_{\mathrm{US}}$ and $M \mathrm{MV}_{\mathrm{MRI}}$ were good; $r$ values ranged between 0.53 and 0.961 , and 
the SEE ranged between 6 and 12\% for healthy adult populations and up to $25.6 \%$ for children with cerebral palsy. Regression equations and measured segments are presented in Table 2. Eight studies did further analysis with a Bland-Altman plot [25, 30, 31, 33, 34, 36, 37, 39] and they found no systematic errors.

A total of 13 segments, reported in $\mathrm{cm}^{3}$, from five studies $[25,31,33,35,39]$ were included in the first plot and plotted against the average (Fig. 2A). They showed an

Table 2 Muscle thickness sites, equations, and correlations

\begin{tabular}{|c|c|c|c|c|}
\hline Segments & Equations & r & SEE $\mathrm{cm}^{3}$ & References \\
\hline$E F$ and $E E$ & $M V_{U S}=L \times(\pi \times M T / 2)^{2}$ & 0.962 & $50.7(7.2 \%)$ & [35] \\
\hline EF & $\mathrm{MV}_{\mathrm{US}}=2.586 \mathrm{BH}-1.259 \mathrm{BW}+7.057 \mathrm{CIR}+0.524\left(\mathrm{~L} \times(\mathrm{MT})^{2}\right)-447.46$ & 0.943 & $6-8 \%$ & [9] \\
\hline EE & $\mathrm{MV}_{\mathrm{US}}=3.478 \mathrm{BH}-0.180 \mathrm{BW}+6.674 \mathrm{CIR}+0.382\left(\mathrm{~L} \times(\mathrm{MT})^{2}\right)-559.36$ & 0.932 & & \\
\hline KE & $\mathrm{MV}_{\mathrm{US}}=(\mathrm{MT} \times 311.732)+(\mathrm{L} \times 53.346)-2058.529$ & $0.824^{*}$ & $175.6(10.6 \%)$ & [33] \\
\hline $\mathrm{EF}$ & $\mathrm{MV}_{\mathrm{US}}=(\mathrm{MT} \times 117.9)+(\mathrm{L} \times 12.6)-494$ & $0.884^{*}$ & $22.1(7.3 \%)$ & [34] \\
\hline EE & $\mathrm{MV}_{\mathrm{US}}=(\mathrm{MT} \times 98.1)+(\mathrm{L} \times 31.9)-984.4$ & $0.842^{*}$ & $40.3(9.8 \%)$ & \\
\hline KE & $M V_{U S}=(M T \times 320.6)+(L \times 110.9)-4437.9$ & $0.787^{*}$ & $198.5(11.1 \%)$ & \\
\hline APF30 & $\mathrm{MV}_{\mathrm{US}}=(\mathrm{MT} \times 219.9)+(\mathrm{L} \times 31.3)-1758$ & $0.832^{*}$ & $78.9(7.6 \%)$ & \\
\hline o Total body (sum of $9 \mathrm{MT}$ ) & $\mathrm{MV}_{\text {TOT }}=0.641 \times \mathrm{MT}_{9} \times \mathrm{BH}-12.087$ & 0.96 & $2.24 \mathrm{~kg}$ & [37] \\
\hline o Total body (sum of $6 \mathrm{MT}$ ) & $\mathrm{MV}_{\text {TOT }}=0.809 \times \mathrm{MT}_{6} \times \mathrm{BH}-4.834$ & 0.96 & $1.8 \mathrm{~kg}$ & \\
\hline o $\operatorname{Arm}(E F+E E+L A F)$ & $\mathrm{MV}_{\text {TOT }}=0.204 \times \mathrm{MT}_{\mathrm{arm}} \times \mathrm{BH}-0.517$ & 0.95 & $0.22 \mathrm{~kg}$ & \\
\hline o Trunk (AB + SUS) & $\mathrm{MV}_{\text {TOT }}=1.303 \times \mathrm{MT}_{\text {trunk }} \times \mathrm{BH}+1.766$ & 0.88 & $1.11 \mathrm{~kg}$ & \\
\hline o Thigh (KE + KF) & $\mathrm{MV}_{\text {TOT }}=0.639 \times \mathrm{MT}_{\text {thigh }} \times \mathrm{BH}-2.972$ & 0.83 & $1.76 \mathrm{~kg}$ & \\
\hline o Lower leg (APF30+ ADF) & $\mathrm{MV}_{\text {TOT }}=0.233 \times \mathrm{MT}_{\text {lower leg }} \times \mathrm{BH}-1.347$ & 0.83 & $0.55 \mathrm{~kg}$ & \\
\hline o Total body (sum of 9 MT) & $\mathrm{MV}_{\text {TOT }}=0.594 \times \mathrm{MT}_{9} \times \mathrm{BH}-11.32$ & 0.91 & $2.75 \mathrm{~kg}$ & \\
\hline o Total body (sum of $6 \mathrm{MT}$ ) & $\mathrm{MV}_{\text {TOT }}=0.831 \times \mathrm{MT}_{6} \times \mathrm{BH}-7.992$ & 0.88 & $2.88 \mathrm{~kg}$ & \\
\hline o $\operatorname{Arm}(E F+E E+L A F)$ & $\mathrm{MV}_{\text {TOT }}=0.132 \times \mathrm{MT}_{\mathrm{arm}} \times \mathrm{BH}+0.093$ & 0.53 & $0.47 \mathrm{~kg}$ & \\
\hline o Trunk (AB + SUS) & $\mathrm{MV}_{\mathrm{TOT}}=0.937 \times \mathrm{MT}_{\text {trunk }} \times \mathrm{BH}+1.794$ & 0.61 & $1.27 \mathrm{~kg}$ & \\
\hline o Thigh (KE + KF) & $\mathrm{MV}_{\text {TOT }}=0.532 \times \mathrm{MT}_{\text {thigh }} \times \mathrm{BH}-2.638$ & 0.81 & $1.39 \mathrm{~kg}$ & \\
\hline \& Lower leg (APF30 + ADF) & $\mathrm{MV}_{\text {TOT }}=0.237 \times \mathrm{MT}_{\text {lower leg }} \times \mathrm{BH}-1.534$ & 0.77 & $0.61 \mathrm{~kg}$ & \\
\hline EF & $\mathrm{MV}_{\mathrm{US}}=60.8 \times \mathrm{MT}+6.48 \times \mathrm{L}-0.709 \times \mathrm{AGE}+51.4 \times \mathrm{SEX}-187.4$ & $0.909^{*}$ & $19.9(10.9 \%)$ & [25] \\
\hline ADD & $\mathrm{MV}_{U S}=5.51 \times \mathrm{MT} \times \mathrm{L}-434.9$ & 0.922 & & [38] \\
\hline APF25 medial & $\mathrm{MV}_{\mathrm{US}}=2.271 \times \mathrm{L}+15.982 \times \mathrm{MT}-41.493$ & $0.831^{*}$ & $4.1(20.6 \%)$ & [32] \\
\hline APF25 lateral & $\mathrm{MV}_{\mathrm{US}}=1.479 \times \mathrm{L}+13.347 \times \mathrm{MT}-28.676$ & $0.779^{*}$ & $3.1(25.6 \%)$ & \\
\hline o Total body (sum of 9 MT) & $\mathrm{MV}_{\mathrm{US}}=384.96 \times\left(\mathrm{MT}_{9} \times \mathrm{BH}\right)-3662.1$ & $0.93^{*}$ & 659 & [31] \\
\hline o $\operatorname{Arm}(E F+E E+L A F)$ & $\mathrm{MV}_{\mathrm{US}}=127.09 \times\left(\mathrm{MT}_{\mathrm{arm}} \times \mathrm{BH}\right)-76.44$ & $0.71^{*}$ & 124 & \\
\hline o Trunk (AB + SUS) & $\mathrm{MV}_{\text {US }}=992.53 \times\left(\mathrm{MT}_{\text {trunk }} \times \mathrm{BH}\right)+363.69$ & $0.65^{*}$ & 565 & \\
\hline o Thigh (KE + KF) & $\mathrm{MV}_{\mathrm{US}}=463.47 \times\left(\mathrm{MT}_{\text {thigh }} \times \mathrm{BH}\right)-1624.3$ & $0.84^{*}$ & 419 & \\
\hline o Lower leg (APF30+ ADF) & $M V_{U S}=176.1 \times\left(M_{\text {lower leg }} \times B H\right)-539.29$ & $0.92^{*}$ & 91 & \\
\hline o Total body (sum of 9 MT) & $\mathrm{MV}_{\mathrm{US}}=364.87 \times\left(\mathrm{MT}_{9} \times \mathrm{BH}\right)-3523$ & $0.89^{*}$ & 731 & \\
\hline ○ Arm (EF+EE + LAF) & $\mathrm{MV}_{\mathrm{US}}=132.68 \times\left(\mathrm{MT}_{\mathrm{arm}} \times \mathrm{BH}\right)-139.4$ & $0.8^{*}$ & 89 & \\
\hline o Trunk (AB+SUS) & $\mathrm{MV}_{\text {US }}=658.79 \times\left(\mathrm{MT}_{\text {trunk }} \times \mathrm{BH}\right)+953.72$ & $0.57^{*}$ & 561 & \\
\hline \& Thigh (KE + KF) & $M V_{\text {US }}=425.40 \times\left(\mathrm{MT}_{\text {thigh }} \times \mathrm{BH}\right)-1506.7$ & $0.9^{*}$ & 286 & \\
\hline \& Lower leg (APF30 + ADF) & $\mathrm{MV}_{\mathrm{US}}=166.19 \times\left(\mathrm{MT}_{\text {lower leg }} \times \mathrm{BH}\right)-439.17$ & $0.88^{*}$ & 103 & \\
\hline KE & $\mathrm{MV}_{\mathrm{US}}=(\mathrm{SEX} \times 267.7)+(\mathrm{MT} \times 249.3)+(\mathrm{L} \times 41.1)-1663.7$ & $0.91^{*}$ & $124.4(12 \%)$ & [39] \\
\hline Total body (sum of 9 MT) & $\mathrm{MV}_{\text {TOT }}=0.645 \times\left(\mathrm{MT}_{9} \times \mathrm{BH}\right)-7.821$ & 0.96 & & [36] \\
\hline
\end{tabular}

$\mathrm{SEE}$, standard error of the estimate. $\mathrm{MV}_{\mathrm{US}}$, estimated muscle volume via US in $\mathrm{cm}^{3}$. MV $\mathrm{TOT}_{\text {, }}$ estimated muscle volume via US in kg. MT, muscle thickness in $\mathrm{cm}$ obtained via US. L, length of the limb in $\mathrm{cm}$. CIR, circumference of upper arm at the same site for MT measuring in $\mathrm{cm}$. BH, body height in meters. BW, body weight in kg. SEX, refers to biological differences between males 1 and females 0 . AGE, values in years

${ }^{\star}$, boys and males. $q$, girls and females. EF, elbow flexors MT obtained at $60 \%$ of anterior arm. EE, elbow extensors, $60 \%$ posterior arm. KE, knee extensors, midpoint of anterior thigh. KF, knee flexors, midpoint of posterior thigh. APF30, ankle plantar flexors, 30\% of the posterior lower leg. APF 25 , ankle plantar flexors, $25 \%$ of the posterior lower leg. ADF, ankle dorsal flexors, $30 \%$ of the anterior lower leg. LAF, obtained at $30 \%$ of the lateral anterior forearm. $A B$, abdominal obtained at a distance $2-3 \mathrm{~cm}$ to the right of the umbilicus. SUS, subscapular, $5 \mathrm{~cm}$ directly below the inferior angle of the scapula. ADD, adductor, $30 \%$ of the medial anterior aspect of the thigh

${ }^{*} r$ in square instead of $r$ 


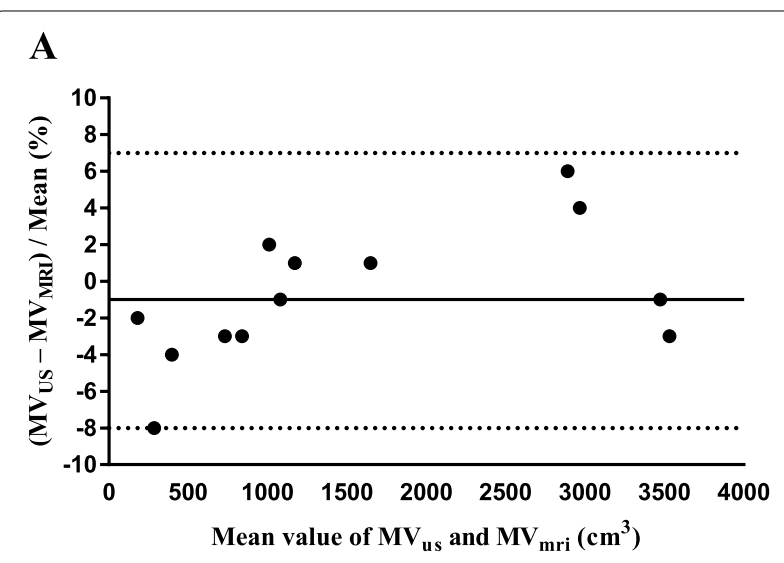

B

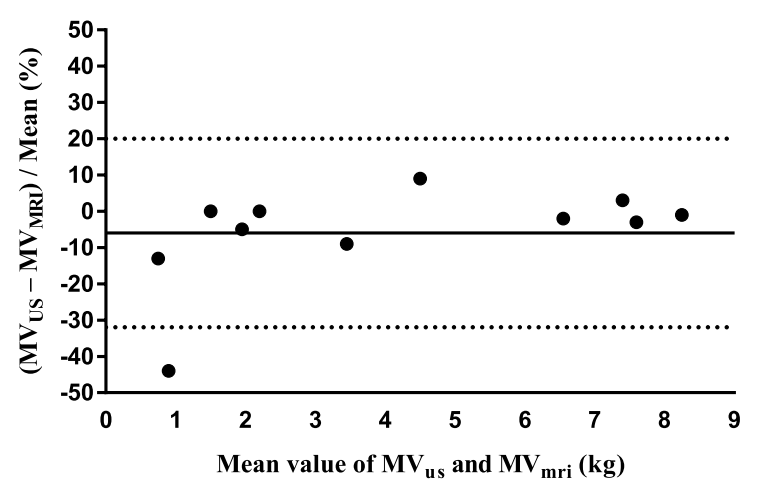

Fig. 2 Bland-Altman agreement, differences plotted in percentages for the studies that reported $\mathrm{MV}_{\mathrm{US}}$. Total body estimates are excluded in the plots. Values in plot $\mathbf{A}$ for the studies that reported data in $\mathrm{cm}^{3}$ : Bias - 1\%, SD 4\%, limits of agreement upper $7 \%$ and lower $-8 \%$.

Values in plot $\mathbf{B}$ for the studies that reported data in $\mathrm{kg}$ : Bias - 6\%, SD $13 \%$, limits of agreement upper $20 \%$ and lower $-32 \%$

even spread in percentage when differences between methods were plotted against the average mean. One measure crossed the lower limit of agreement, namely the anterior upper arm data reported from Miyatani et al. [35]. Three studies reported values in $\mathrm{kg}$ [30, 36, 37] although when total body estimates were excluded from the Bland-Altman analysis, two studies remained [30, 37]. Midorikawa et al. [30] tested the equation derived from Sanada et al. [37] and eleven segments were plotted against the average (Fig. 2B). In this plot, the data show a larger spread, illustrated by the Y-axis in the plots in Fig. 2. Two data points are the main reason for this: the arm $(-44 \%)$ and lower leg $(-13 \%)$ segments calculated from measures on prepubertal children reported by Midorikawa et al. [30]. The arm segment in prepubertal children crossed the lower limit of agreement.

The overall strength and quality of the evidence was rated as "low quality" as defined by the GRADE system. Two reasons for this were that eleven of twelve articles originated from the same study group and descriptive data were missing in several reports, such as means for MV [9, 32, 34, 38], and there were no individual data published in any of the studies.

\section{Discussion}

The most important finding of this investigation was that the validity of US-derived equations based on MT is specific to the populations from which it is developed. Midorikawa et al. [30] tested the validity of $\mathrm{MV}_{\mathrm{US}}$ for adolescents and prepubertal children based on equations previously derived from adults. They found inferior validity for prepubertal children, though no significant difference for adolescents. Their Bland-Altman analysis showed a relatively high level of variability for both adolescents and prepubertal children. Nakatani et al. [39] found that prediction equations developed for young adults were not valid for middle-aged and older men and women, and Toda et al. [36] showed that prediction equations derived from a sedentary population were not applicable for young male athletes. In our study, MT correlates well with MV (Table 2), neither did we find any systematic errors between the methods used to estimate $\mathrm{MV}_{\mathrm{US}}$ and $M \mathrm{MV}_{\mathrm{MRI}}$. The SEE varied between 6 and $12 \%$ in a healthy adult population and up to $25.6 \%$ for children with cerebral palsy (Table 2).

Correlations in our review agreed with previous reviews by Abe et al. $[40,41]$ investigating the association between MT and MV for the upper extremity [40] and the lower extremity [41] respectively. However, Abe et al. also included studies with reference methods such as CT and cadavers [25, 33, 34, 38]. Nijholt et al. [42] conducted a systematic review investigating the validity of US-derived prediction equations to estimate $\mathrm{MV}$ in an elderly population aged $>60$, using dual-energy $x$-ray absorptiometry (DEXA) as a reference. They reported $\mathrm{r}^{2}$ values of 0.92 and 0.96 . To our knowledge, no other systematic reviews have investigated the validity of $M V_{U S}$ with $M V_{M R I}$ as a reference.

Thirty-six different prediction equations were identified in this systematic review and the studies included in our review used different variables in their regression analysis in addition to MT (Table 2). Miyatani et al. [35] performed the first prediction equations with the formula for calculating a cylinder with limb length as a variable. The same group later reported that the prediction improved when MT was combined with limb length, compared to MT alone [34]. Eight of the studies we included used limb length as a variable in their regressions $[9,25,32-35,38,39]$. Limb length measurements were made with a measuring tape between anatomical landmarks and therefore represent an approximation of the actual muscle length (ML). When $\mathrm{MV}_{\mathrm{MRI}}$ is determined, ML is defined as the distance between the most 
proximal and the most distal images in which the muscle is visible [34]. With a linear US transducer, which was used in all the included studies, a similar approach as for $\mathrm{MV}_{\mathrm{MRI}}$ of measuring actual ML with repeated measurements along the limb would have been challenging and more time consuming than to determine limb length with a measuring tape. However, it is possible for an experienced sonographer to use more precise landmarks for measuring ML, by identifying the origin and insertion of specific muscles. This is still more time consuming but interesting if the length and thickness of specific muscles were to be compared instead of the limb length and thickness of a muscle group. Body height $(\mathrm{BH})$ was used to express the length factor of the muscle in three of the equations [31, 36, 37], and one study, Fukunaga et al. [9], used both $\mathrm{BH}$ and limb length as variables.

Miyatani et al. [34] reported that the relative contribution of limb length to predict the measured MV in the multiple regression equations varied from $18 \%$ for the elbow flexors to $37.7 \%$ for the knee extensors, which was less than the MT contribution. Akagi et al. [25] included both sex and a wider range of ages when reporting the relative contribution for the elbow flexors. They found that the contribution of MT predicting MV was about 2.5 times higher than the contribution of limb length (13.6\%). Also, the relative contribution of sex to predict MV (34.3\%) was nearly equal to that of MT (33.9\%) and that a decrease in MV did not correspond to a decrease in MT with ageing when the sex variable was statistically controlled for. Park et al. [32] noticed that the relative contribution of limb length for ankle plantar flexors' medial and lateral head was $62.9 \%$ and $59.1 \%$ in the $M V_{U S}$ prediction based on MT in two- to six-year-old children suffering bilateral spasticity. They also conducted a multiple regression model for predicting MV based on ACSA and reported that the relative contribution of limb length for predicting MV was $24.8 \%$ for the medial head and $18.0 \%$ for the lateral, while ACSA contributed with $65.6 \%$ and $67.8 \%$, respectively. It is not surprising that MT contributes the least in the group of young children with impaired muscle function. Children with unilateral spastic cerebral palsy have, on average, smaller volume on their affected side compared to the less affected side [43]. This, in combination with smaller mean fibre size and smaller CSA in children's muscle mass due to the larger proportion of Type 1 muscle fibres [44], probably explains why the contribution of limb length was superior to MT in the study by Park et al. [32].

Despite the different variables included in the regression equations, there is no clear difference in SEE values, with the exception of the study on children with cerebral palsy reporting SEE of $20.6 \%$ for the medial gastrocnemius and $25.6 \%$ of the lateral gastrocnemius [32]. The children suffered bilateral spasticity, making it hard to standardise the joint positions for the measurements. It is important to standardise joint position because it will influence the muscle's architecture [45]. The standardisation procedure used by Park et al. [32] was in the prone position with the ankle in resting position. Resting position may vary within and between subjects depending on the severity of the spasticity and Park et al. [32] suggested that better standardisation of the MT measurement in children with cerebral palsy is required. Miyatani et al. [34] measured the plantar flexors in a standing position in healthy adults, thereby making sure that the ankle joint was in the same position for every measurement, leading to a SEE of 7.6\%. Considering only healthy adults would leave us with the range of SEE $6-12 \%$ and thus, less variation across the studies we included.

Developing accurate prediction equations based on MT is complex. One factor that may contribute to this complexity is that the measurement of MT with US does not differentiate between contractile and non-contractile intramuscular tissue (NCIT), while the method for $\mathrm{MV}_{\mathrm{MRI}}$ excludes NCIT when digitizing the images [34]. NCIT refers to intramuscular adipose tissue and intramuscular connective tissue, and is influenced by different factors including comorbidities, age, and physical activity [46, 47]. Increased age is associated with an increase in the relative amount of NCIT within the muscle [48]. Comorbidities and inactivity are associated with increased NCIT, whereas exercise is associated with reduced levels of NCIT [46, 47].

Moreover, the changes in MV do not only depend on MT, but also on muscle width [25] and fascicle length [49]. This is especially relevant in the context of differences in pinnation angle of individual muscle, leading to a discrepancy between ACSA and physiological CSA (PCSA) [50]. ACSA represents the CSA of the muscle perpendicular to its longitudinal axis and does not represent the CSA perpendicular to all fibres in a pinnate muscle. PCSA refers to the CSA perpendicular to the fascicle plane and represents the total CSA of all the muscle fibres within the muscle [51]. PCSA is proportional to muscle force [52], increases with a larger angle of pinnation and is usually calculated from the ratio of MV to fascicle length, multiplied by the cosine of pinnation angle [50]. Aagaard et al. [53] reported that after 14 weeks of resistance exercise, vastus lateralis fibre pinnation angle increased in eleven untrained males. This allowed PCSA of single muscle fibres and thereby maximal force generating capacity to increase significantly more $(+16 \%)$ than ACSA and MV (+10\%). Consequently, changes in PCSA caused by exercise or inactivity may not automatically reflect the change in ACSA and MV [53]. Narici et al. [54] described that ageing is associated with reduced 
fascicle length and pinnation angle which could result in a decrease of PCSA, an alternation expected to have implications for muscle function [54]. Both the length of the muscle fascicles and the pinnation angle can be measured using US. One limitation is the relatively small field of view, making it hard to measure the fascicle length in certain muscles without some degree of estimation [55]. None of the equations in our study included pinnation angles or fascicle length but taken together with NCIT, this may, to some extent, explain why our review indicates that US-derived prediction equations are specific to the population from which they are derived. In order to develop a more generalised prediction equation, we believe it is important to account for comorbidities, age, sex and physical activity levels.

The agreement between two methods is illustrated in our Bland-Altman plot (Fig. 2). To minimize the influence of the variation in size of segments, the differences were plotted in percentages [56]. Furthermore, the total body data were excluded due to the large values that would have displaced values on the $\mathrm{X}$-axis, and thereby been unrepresentative for the segment data. Whether to plot against the average or against the reference is debatable $[57,58]$. If MRI is considered the gold standard, and the purpose is to develop another method to reach agreement with MRI, plotting against the reference seems to be more appropriate. On the other hand, with an unknown true value for MV, plotting against the average mean is most likely accurate. Bland and Altman suggest that plotting differences against the standard method might be misleading and to plot against the average is more correct in almost all applications for medical measurements [57]. Since the manual slice-by-slice segmentation technique to measure $\mathrm{MV}_{\mathrm{MRI}}$ has, to our knowledge, only been validated against the water displacement method in one study [59], the choice of plotting against the average is preferable. Figure $2 \mathrm{~B}$ illustrates data from only two studies, and Midorikawa et al. [30] tested the equation derived from Sanada et al. [37] on different populations. Consequently, the strength of Fig. $2 \mathrm{~B}$ is that the same equation was used. However, the downside is that the equation was not derived for prepubertal children and adolescents, resulting in a larger BIAS $(-6 \%)$ compared with the data in Fig. $2 \mathrm{~A}(-1 \%)$. Figure $2 \mathrm{~A}$ is the exact opposite to Fig. $2 \mathrm{~B}$ where different equations are mixed, but they are derived for a specific population, resulting in a better outcome.

When conducting an MRI scan, the subject is commonly placed in a supine position, even though it is possible to scan subjects in an upright position [60]. In the present review, almost all studies placed their subjects in a supine position when measuring $\mathrm{MV}_{\mathrm{MRI}}$ (Table 1) but placed their subjects in a standing position when measuring MT (Table 1). We do not know the reason for this. It is also unclear whether this has any significance for the validity of $\mathrm{MV}_{\mathrm{US}}$. One could speculate that muscle shape changes slightly in different positions and that USderived MT measured in the same position as the reference method would make the predictions better, thereby increasing the validity of $\mathrm{MV}_{\mathrm{US}}$.

Our eligibility criteria were narrow and therefore all the studies included had almost the same design. This can be regarded as a strength since it makes it easier to comprehend the results. Unfortunately, this is also a weakness since eleven out of twelve studies were conducted in the same country and many of those studies came from the same research group. This affected the strength of the evidence synthesis according to GRADE along with some descriptive data that were missing. Another limitation is that the number of studies including children in our study is small and just one of the included studies [32] examined a population with medical condition. Only one study [31] developed equations for healthy children which makes it difficult to draw any meaningful conclusion for prepubertal children or for populations with disorders affecting muscle volume and emphasizes the need for more studies regarding the validity of $M V_{U S}$ in this field.

The results from the present systematic review are interesting and applicable in both scientific and clinical settings, for example in the field of sports medicine where a change in muscle mass is often a main outcome. Franchi et al. [61] correlated MT with ACSA over a twelve-week period of resistance exercise and reported changes in vastus lateralis MT that significantly correlated with the changes in mid-thigh ACSA. Comparisons between changes in $M_{U S}$ based on MT and $M V_{M R I}$ in conjunction with a period of resistance exercise would be interesting for future studies.

Another topic for future research would be to study whether the location of the measuring site along individual muscles or muscle groups can improve the predictions. Today, MT is measured at one location for each segment. The location selected is intended to correspond to the point of maximal CSA of the muscle [25, 35]. Yamauchi et al. [62] did measurements of MT with MRI at $10 \%$ intervals of the individual quadriceps muscles and compared how well different MT locations predicted MV. They found site-specific variations for how well MT correlated with MV between individual quadriceps muscles. For example, at mid-length, correlations between femur length $\times$ MT and MV for individual muscles, ranged between $\mathrm{r}^{2} 0.73-0.96$ [62]. Ogawa et al. [38] also compared different measuring sites along the medial anterior aspect of the thigh and found that, for the adductor muscle group, the more 
proximal sites were better correlated to MV. How the location of measuring sites, or the addition of extra measuring sites, can influence the validity of prediction equations based on MT is still an open question and an area for future research.

From a clinical point of view, the present study has listed all the segments, sex, and the derived equations and compiled them into Table 2, helping clinicians with a user-friendly reference card to estimate MV with the help of US. This may be particularly helpful when monitoring progress after injury or surgery and may assist in making return-to-play decisions by giving clinicians a quick and simple prediction of the athlete's MV.

\section{Conclusions}

We conclude that the validity of US-derived equations based on MT is specific to the populations from which it is developed. The agreement with $M V_{M R I}$ is moderate with SEE ranging between 6 and 12\% in healthy adult populations. Suggestions for future research are to investigate whether testing positions, the location of measuring sites or increasing the number of measuring sites could improve the validity of prediction equations.

\section{Abbreviations \\ ACL: Anterior cruciate ligament; ACSA: Axial anatomical cross-sectional area; BH: Body height; BW: Body weight; CINAHL: Cumulative index to nursing \& allied health literature; CT: Computed tomography; DEXA: Dual-energy $x$-ray absorptiometry; GRADE: Group reading assessment and diagnostic evaluation; MeSH: Medical subject headings; ML: Muscle length; MRI: Magnetic resonance imaging; MT: Muscle thickness; MV: Muscle volume; MV estimating MV measured with MRI based on ACSA; NCIT: Non-contractile intramuscular tissue; PCSA: Physiological cross-sectional area; PRISMA: Preferred reporting items for systematic reviews and meta-analyses; QUADAS: Quality assessment of diagnostic accuracy studies; SD: Standard deviation; SEE: Standard error of the estimate; SEM: Standard error of the mean; US: Ultrasonography; MV Us: The method for estimating MV measured with US based on MT.}

\section{Acknowledgements}

Not applicable.

\section{Authors' contributions}

$\mathrm{RL}$ and FW designed the study, conducted the literature review, analysed the data, and drafted the manuscript. RL created the figures. AS contributed to drafting the manuscript. MH contributed to designing the study and drafting the manuscript. All authors read and approved the final manuscript.

\section{Funding}

Open access funding provided by Karolinska Institute.

\section{Availability of data and materials}

All data generated or analysed during this study are included in this published article.

\section{Declarations}

\section{Ethics approval and consent to participate}

All studies included in the present investigation declared that written or informed consent had been given by study participants.
Consent for publication

Not applicable.

\section{Competing interests}

The authors declare that they have no conflicts of interest.

\section{Author details}

'Stockholm Sports Trauma Research Centre, Department of Molecular Medicine and Surgery, Karolinska Institute, Stockholm, Sweden. ${ }^{2}$ Centre for Medical Imaging, University Hospital, Uppsala University, Uppsala, Sweden.

Received: 9 February 2021 Accepted: 29 June 2021

Published online: 05 July 2021

\section{References}

1. Frontera WR, Ochala J. Skeletal muscle: a brief review of structure and function. Calcif Tissue Int. 2015;96(3):183-95.

2. Giudice J, Taylor JM. Muscle as a paracrine and endocrine organ. Curr Opin Pharmacol. 2017;34:49-55.

3. Sergi G, Trevisan C, Veronese N, Lucato P, Manzato E. Imaging of sarcopenia. Eur J Radiol. 2016;85(8):1519-24.

4. Liu P, Hao Q, Hai S, Wang H, Cao L, Dong B. Sarcopenia as a predictor of all-cause mortality among community-dwelling older people: a systematic review and meta-analysis. Maturitas. 2017;103:16-22.

5. Zhang X, Zhang W, Wang C, Tao W, Dou Q, Yang Y. Sarcopenia as a predictor of hospitalization among older people: a systematic review and meta-analysis. BMC Geriatr. 2018;18(1):188.

6. Westcott WL. Resistance training is medicine: effects of strength training on health. Curr Sports Med Rep. 2012;11(4):209-16.

7. McLeod JC, Stokes T, Phillips SM. Resistance exercise training as a primary countermeasure to age-related chronic disease. Front Physiol. 2019;10:645.

8. Tyrovolas S, Panagiotakos D, Georgousopoulou E, Chrysohoou C, Tousoulis D, Haro JM, et al. Skeletal muscle mass in relation to 10 year cardiovascular disease incidence among middle aged and older adults: the ATTICA study. J Epidemiol Commun Health. 2020;74(1):26-31.

9. Fukunaga T, Miyatani M, Tachi M, Kouzaki M, Kawakami Y, Kanehisa H. Muscle volume is a major determinant of joint torque in humans. Acta Physiol Scand. 2001;172(4):249-55.

10. Baxter JR, Piazza SJ. Plantar flexor moment arm and muscle volume predict torque-generating capacity in young men. J Appl Physiol (1985). 2014;116(5):538-44

11. Meier WA, Marcus RL, Dibble LE, Foreman KB, Peters CL, Mizner RL, et al. The long-term contribution of muscle activation and muscle size to quadriceps weakness following total knee arthroplasty. J Geriatr Phys Ther. 2009;32(2):79-82.

12. Kuenze CM, Blemker SS, Hart JM. Quadriceps function relates to muscle size following ACL reconstruction. J Orthop Res. 2016;34(9):1656-62.

13. Goodman CA, Frey JW, Mabrey DM, Jacobs BL, Lincoln HC, You JS, et al. The role of skeletal muscle mTOR in the regulation of mechanical loadinduced growth. J Physiol. 2011;589(Pt 22):5485-501.

14. Foster DM, Barrett PH, Toffolo G, Beltz WF, Cobelli C. Estimating the fractional synthetic rate of plasma apolipoproteins and lipids from stable isotope data. J Lipid Res. 1993;34(12):2193-205.

15. Gasier HG, Riechman SE, Wiggs MP, Previs SF, Fluckey JD. A comparison of $2 \mathrm{H} 2 \mathrm{O}$ and phenylalanine flooding dose to investigate muscle protein synthesis with acute exercise in rats. Am J Physiol Endocrinol Metab. 2009;297(1):E252-9.

16. Bandholm T, Sonne-Holm S, Thomsen C, Bencke J, Pedersen SA, Jensen BR. Calf muscle volume estimates: implications for botulinum toxin treatment? Pediatr Neurol. 2007;37(4):263-9.

17. Pons C, Borotikar B, Garetier M, Burdin V, Ben Salem D, Lempereur $\mathrm{M}$, et al. Quantifying skeletal muscle volume and shape in humans using MRI: a systematic review of validity and reliability. PLOS ONE. 2018;13(11):e0207847.

18. Tracy BL, Ivey FM, Jeffrey Metter E, Fleg JL, Siegel EL, Hurley BF. A more efficient magnetic resonance imaging-based strategy for measuring quadriceps muscle volume. Med Sci Sports Exerc. 2003;35(3):425-33. 
19. Dankel SJ, Buckner SL, Jessee MB, Mattocks KT, Mouser JG, Counts BR, et al. Post-exercise blood flow restriction attenuates muscle hypertrophy. Eur J Appl Physiol. 2016;116(10):1955-63.

20. Lowery RP, Joy JM, Loenneke JP, de Souza EO, Machado M, Dudeck JE, et al. Practical blood flow restriction training increases muscle hypertrophy during a periodized resistance training programme. Clin Physiol Funct Imaging. 2014;34(4):317-21.

21. Loenneke JP, Kim D, Fahs CA, Thiebaud RS, Abe T, Larson RD, et al. The influence of exercise load with and without different levels of blood flow restriction on acute changes in muscle thickness and lactate. Clin Physiol Funct Imaging. 2017;37(6):734-40.

22. Schoenfeld BJ, Grgic J, Contreras B, Delcastillo K, Alto A, Haun C, et al. To flex or rest: does adding no-load isometric actions to the inter-set rest period in resistance training enhance muscular adaptations? A randomized-controlled trial. Front Physiol. 2019;10:1571.

23. Giles LS, Webster KE, McClelland JA, Cook J. Can ultrasound measurements of muscle thickness be used to measure the size of individual quadriceps muscles in people with patellofemoral pain? Phys Ther Sport. 2015;16(1):45-52.

24. Abe T, Nakatani M, Loenneke JP. Relationship between ultrasound muscle thickness and MRI-measured muscle cross-sectional area in the forearm: a pilot study. Clin Physiol Funct Imaging. 2018;38(4):652-5.

25. Akagi R, Takai Y, Kato E, Wakahara T, Ohta M, Kanehisa H, et al. Development of an equation to predict muscle volume of elbow flexors for men and women with a wide range of age. Eur J Appl Physiol. 2010;108(4):689-94.

26. Bland JM, Altman DG. Statistical methods for assessing agreement between two methods of clinical measurement. Lancet. 1986;1(8476):307-10

27. Moher D, Liberati A, Tetzlaff J, Altman DG, Group atP. preferred reporting items for systematic reviews and meta-analyses: the PRISMA statement. Ann Intern Med. 2009;151(4):264-9.

28. Whiting P, Rutjes AW, Reitsma JB, Bossuyt PM, Kleijnen J. The development of QUADAS: a tool for the quality assessment of studies of diagnostic accuracy included in systematic reviews. BMC Med Res Methodol. 2003:3:25.

29. Guyatt GH, Oxman AD, Vist GE, Kunz R, Falck-Ytter Y, Alonso-Coello P, et al. GRADE: an emerging consensus on rating quality of evidence and strength of recommendations. BMJ. 2008;336(7650):924-6.

30. Midorikawa T, Sanada K, Yoshitomi A, Abe T. Is the use of ultrasoundderived prediction equations for adults useful for estimating total and regional skeletal muscle mass in Japanese children? Br J Nutr. 2009;101(1):72-8.

31. Midorikawa T, Ohta M, Hikihara Y, Torii S, Sakamoto S. Prediction and validation of total and regional skeletal muscle volume using B-mode ultrasonography in Japanese prepubertal children. Br J Nutr. 2015;114(8):1209-17.

32. Park ES, Sim E, Rha DW, Jung S. Estimation of gastrocnemius muscle volume using ultrasonography in children with spastic cerebral palsy. Yonsei Med J. 2014;55(4):1115-22.

33. Miyatani M, Kanehisa H, Kuno S, Nishijima T, Fukunaga T. Validity of ultrasonograph muscle thickness measurements for estimating muscle volume of knee extensors in humans. Eur J Appl Physiol. 2002;86(3):203-8.

34. Miyatani M, Kanehisa H, Ito M, Kawakami Y, Fukunaga T. The accuracy of volume estimates using ultrasound muscle thickness measurements in different muscle groups. Eur J Appl Physiol. 2004;91(2-3):264-72.

35. Miyatani M, Kanehisa H, Fukunaga T. Validity of bioelectrical impedance and ultrasonographic methods for estimating the muscle volume of the upper arm. Eur J Appl Physiol. 2000;82(5-6):391-6.

36. Toda Y, Kimura T, Taki C, Kurihara T, Homma T, Hamaoka T, et al. New ultrasonography-based method for predicting total skeletal muscle mass in male athletes. J Phys Ther Sci. 2016;28(5):1556-9.

37. Sanada K, Kearns CF, Midorikawa T, Abe T. Prediction and validation of total and regional skeletal muscle mass by ultrasound in Japanese adults. Eur J Appl Physiol. 2006;96(1):24-31.
38. Ogawa M, Mitsukawa N, Bemben MG, Abe T. Ultrasound assessment of adductor muscle size using muscle thickness of the thigh. J Sport Rehabil. 2012;21(3):244-8.

39. Nakatani M, Takai Y, Akagi R, Wakahara T, Sugisaki N, Ohta M, et al. Validity of muscle thickness-based prediction equation for quadriceps femoris volume in middle-aged and older men and women. Eur J Appl Physiol. 2016;116(11-12):2125-33.

40. Abe T, Loenneke JP, Thiebaud RS, Loftin M. Morphological and functional relationships with ultrasound measured muscle thickness of the upper extremity and trunk. Ultrasound. 2014;22(4):229-35.

41. Abe T, Loenneke JP, Thiebaud RS. Morphological and functional relationships with ultrasound measured muscle thickness of the lower extremity: a brief review. Ultrasound. 2015;23(3):166-73.

42. Nijholt W, Scafoglieri A, Jager-Wittenaar H, Hobbelen JSM, van der Schans CP. The reliability and validity of ultrasound to quantify muscles in older adults: a systematic review. J Cachexia Sarcopenia Muscle. 2017:8(5):702-12.

43. D'Souza A, Bolsterlee B, Lancaster A, Herbert RD. Muscle architecture in children with cerebral palsy and ankle contractures: an investigation using diffusion tensor imaging. Clin Biomech (Bristol, Avon). 2019;68:205-11.

44. Lexell J, Sjöström M, Nordlund AS, Taylor CC. Growth and development of human muscle: a quantitative morphological study of whole vastus lateralis from childhood to adult age. Muscle Nerve. 1992;15(3):404-9.

45. Gallina A, Render JN, Santos J, Shah H, Taylor D, Tomlin T, et al. Influence of knee joint position and sex on vastus medialis regional architecture. Appl Physiol Nutr Metab. 2018;43(6):643-6.

46. Mikkelsen UR, Agergaard J, Couppé C, Grosset JF, Karlsen A, Magnusson SP, et al. Skeletal muscle morphology and regulatory signalling in endurance-trained and sedentary individuals: The influence of ageing. Exp Gerontol. 2017:93:54-67.

47. Marcus RL, Addison O, Kidde JP, Dibble LE, Lastayo PC. Skeletal muscle fat infiltration: impact of age, inactivity, and exercise. J Nutr Health Aging. 2010;14(5):362-6.

48. Csapo R, Malis V, Sinha U, Du J, Sinha S. Age-associated differences in triceps surae muscle composition and strength - an MRI-based crosssectional comparison of contractile, adipose and connective tissue. BMC Musculoskelet Disord. 2014;15:209.

49. Seynnes OR, de Boer M, Narici MV. Early skeletal muscle hypertrophy and architectural changes in response to high-intensity resistance training. J Appl Physiol (1985). 2007;102(1):368-73.

50. Narici M, Franchi M, Maganaris C. Muscle structural assembly and functional consequences. J Exp Biol. 2016;219(Pt 2):276-84.

51. Lieber RL, Fridén J. Functional and clinical significance of skeletal muscle architecture. Muscle Nerve. 2000;23(11):1647-66.

52. Powell PL, Roy RR, Kanim P, Bello MA, Edgerton VR. Predictability of skeletal muscle tension from architectural determinations in guinea pig hindlimbs. J Appl Physiol Respir Environ Exerc Physiol. 1984;57(6):1715-21.

53. Aagaard $P$, Andersen $J$, Dyhre-Poulsen P, Leffers AM, Wagner A, Magnusson SP, et al. A mechanism for increased contractile strength of human pennate muscle in response to strength training: changes in muscle architecture. J Physiol. 2001:534(Pt. 2):613-23.

54. Narici MV, Maganaris CN, Reeves ND, Capodaglio P. Effect of aging on human muscle architecture. J Appl Physiol (1985). 2003;95(6):2229-34.

55. Franchi MV, Raiteri BJ, Longo S, Sinha S, Narici MV, Csapo R. Muscle architecture assessment: strengths, shortcomings and new frontiers of in vivo imaging techniques. Ultrasound Med Biol. 2018;44(12):2492-504.

56. Giavarina D. Understanding Bland Altman analysis. Biochem Med (Zagreb). 2015;25(2):141-51.

57. Bland JM, Altman DG. Comparing methods of measurement: why plotting difference against standard method is misleading. Lancet. 1995:346(8982):1085-7.

58. Krouwer JS. Why Bland-Altman plots should use $X$, not $(Y+X) / 2$ when $X$ is a reference method. Stat Med. 2008;27(5):778-80. 
59. Eng CM, Abrams GD, Smallwood LR, Lieber RL, Ward SR. Muscle geometry affects accuracy of forearm volume determination by magnetic resonance imaging (MRI). J Biomech. 2007;40(14):3261-6.

60. Botchu R, Bharath A, Davies AM, Butt S, James SL. Current concept in upright spinal MRI. Eur Spine J. 2018;27(5):987-93.

61. Franchi MV, Longo S, Mallinson J, Quinlan JI, Taylor T, Greenhaff PL, et al. Muscle thickness correlates to muscle cross-sectional area in the assessment of strength training-induced hypertrophy. Scand J Med Sci Sports. 2018:28(3):846-53.

62. Yamauchi K, Yoshiko A, Suzuki S, Kato C, Akima H, Kato T, et al. Estimation of individual thigh muscle volumes from a single-slice muscle cross-sectional area and muscle thickness using magnetic resonance imaging in patients with knee osteoarthritis. J Orthop Surg (Hong Kong). 2017;25(3):2309499017743101.

\section{Publisher's Note}

Springer Nature remains neutral with regard to jurisdictional claims in published maps and institutional affiliations.
Ready to submit your research? Choose BMC and benefit from:

- fast, convenient online submission

- thorough peer review by experienced researchers in your field

- rapid publication on acceptance

- support for research data, including large and complex data types

- gold Open Access which fosters wider collaboration and increased citations

- maximum visibility for your research: over $100 \mathrm{M}$ website views per year

At BMC, research is always in progress.

Learn more biomedcentral.com/submissions 